\title{
Article \\ A Design Method for a Variable Combined Brake System for Motorcycles Applying the Adaptive Control Method
}

\author{
Yuan-Ting Lin ${ }^{1, *(\mathbb{D}}$, Chyuan-Yow Tseng ${ }^{2}{ }^{\mathbb{D}}$, Jao-Hwa Kuang ${ }^{1}$ and Yeong-Maw Hwang ${ }^{1}$ \\ 1 Department of Mechanical and Electromechanical Engineering, National Sun Yat-sen University, \\ Kaohsiung 804201, Taiwan; kuang@faculty.nsysu.edu.tw (J.-H.K.); ymhwang@mail.nsysu.edu.tw (Y.-M.H.) \\ 2 Department of Vehicle Engineering, National Pingtung University of Science and Technology, \\ Pingtung 912301, Taiwan; chyuan@mail.npust.edu.tw \\ * Correspondence: yuanting@g-mail.nsysu.edu.tw
}

Citation: Lin, Y.-T.; Tseng, C.-Y.; Kuang, J.-H.; Hwang, Y.-M. A Design Method for a Variable Combined Brake System for Motorcycles Applying the Adaptive Control Method. Machines 2021, 9, 31. https://doi.org/10.3390/ machines 9020031

Academic Editor:

Francesco Castellani

Received: 13 January 2021

Accepted: 30 January 2021

Published: 5 February 2021

Publisher's Note: MDPI stays neutral with regard to jurisdictional claims in published maps and institutional affiliations.

Copyright: (c) 2021 by the authors. Licensee MDPI, Basel, Switzerland. This article is an open access article distributed under the terms and conditions of the Creative Commons Attribution (CC BY) license (https:// creativecommons.org/licenses/by/ $4.0 /)$.

\begin{abstract}
The variable combined brake system (VCBS) is a mechanism for motorcycles to simultaneously activate the front and rear brake systems by using one brake lever or pedal. The purpose is to reduce the risk of rollover accidents due to misuse of the front brake when panic braking. Due to its ability in a wide variation range of braking force distribution (BFD) ratios between the front and rear wheels, the VCBS can simultaneously achieve high braking effort and driving comfort performances, provided that the BFD ratio is designed appropriately. This paper aimed to develop the design method for the VCBS. A mathematical model of the VCBS mechanism is derived, and a parameter matching design method that applies adaptive control theory is proposed. A prototype of VCBS is designed and built based on the proposed method. The straight-line braking test results show that the motorcycle equipped with the VCBS prototype effectively obtained a high braking performance in deceleration. The obtained maximum deceleration is an average of $6.37 \mathrm{~m} / \mathrm{s}^{2}(0.65 \mathrm{~g})$ under an average handbrake lever force of $154.29 \mathrm{~N}$. For front brake failure, maximum deceleration is obtained at an average of $3.38 \mathrm{~m} / \mathrm{s}^{2}(0.34 \mathrm{~g})$, which is higher than the homologation requirement of $2.9 \mathrm{~m} / \mathrm{s}^{2}$.
\end{abstract}

Keywords: motorcycle; brake system; CBS; variable combined brake system; adaptive control; cam profile design

\section{Introduction}

A combined braking system (CBS) is a mechanism that links the front and rear brake systems of a motorcycle. The driver only needs to press a single handbrake lever to activate the front and rear wheels simultaneously. In a conventional independent brake system, the left handbrake lever brakes the rear wheel, while the right handbrake lever controls the front wheel brake. It quite often happens that the driver accidentally activates the front wheel brake alone when panic braking, causing rollover accidents. Therefore, the European Union enacts regulations to compel anti-lock braking systems (ABS) or CBS on motorcycles. Countries around the world have followed up to promote this regulation.

The advantages of using a CBS have been studied. Previous work [1,2] has shown that a CBS that appropriately allocates front and rear wheels' braking forces can reduce the risk of crashing accidents due to poor driving skills. When straight-line braking, regardless of whether the driver's skills are proficient or not, a motorcycle equipped with a CBS can be braked with higher decelerations and lower yaw rates than the conventional independent brake system. When braking during cornering, the motorcycle using a CBS produced less roll motion than the one using the front brake alone [3].

Application of the front braking force generates a torque to increase the motorcycle's yaw rate. On the other hand, the rear braking force generates a stabilizing torque to align the motorcycle with its original direction. Therefore, when a motorcycle is braked during cornering with a small left handbrake lever force, a CBS allocating more rear braking force than the front brake is beneficial to the motorcycle's directional stability. However, 
a rear braking force that is too large could lead the driver to feel cornering difficulty or even lead to server rear-tire sideslip. Therefore, a previous study [4] put the optimal rear braking force for their CBS through simulations to avoid rear wheel locking during cornering maneuvers.

For small and median force braking maneuvers, driving comfort is of most concern. A front braking force that is too large tends to dive the motorcycle's body, leading to feelings of discomfort. In contrast, the rear braking force provides a squat torque to the vehicle body, which is comfortable for the driver. Therefore, a rear brake with a more considerable allocation than the front brake is better for small force braking maneuvers (e.g., Handbrake force < 100 N). Kazuhiko Tani et al. [5] suggested that the CBS should activate the rear wheel first for all road conditions to respond the same as that of the independent brake system. The purpose is to reduce the discomfort felt by drivers who are new to the CBS. Most importantly, the front wheel being locked first can cause the danger of rollover accidents.

Based on the above discussions, a CBS is required to provide an appropriate braking force distribution (BFD) ratio so that the driver can generate sufficient braking force under most driving conditions using only the left handbrake lever. The right handbrake lever is for auxiliary and backup purposes only. Most of the current CBS products on the market are designed with a constant leverage ratio for braking force allocation (called simple CBS). Simple CBS has the advantages of low costs and being simple to implement. However, due to limited design degree-of-freedom (DOF) constraints and the requirement of braking the rear wheel first, simple CBS is generally designed with a small front braking force allocation. Due to the load transfer effect, the front tire can offer a higher braking force than the rear tire. Excessive braking forces on the rear tire can cause it to become locked. Thus, a high enough front braking force distribution ratio is required to acquire high deceleration while keeping the motorcycle's stability during emergence braking. Otherwise, a severe skid on the rear tire can occur, leading to unsatisfactory performance in deceleration and stability. A novel mechanism called the variable combined system (VCBS) has been proposed in our previous work [6] to render the problem mentioned above.

The basic idea behind the VCBS is shown in Figure 1 schematically. The input force $F$ is from the left handbrake lever. A floating swingarm is utilized to distribute the input force to the front and rear brake systems. The input force acts on the swingarm's cam surface through a roller. The magnitude of the input force, the balance of the spring force and the force component due to the cam determine the position of the roller and the force ratio of the front and rear brake systems. Therefore, the number of VCBS's DOF can be increased to meet the requirements mentioned above simultaneously.

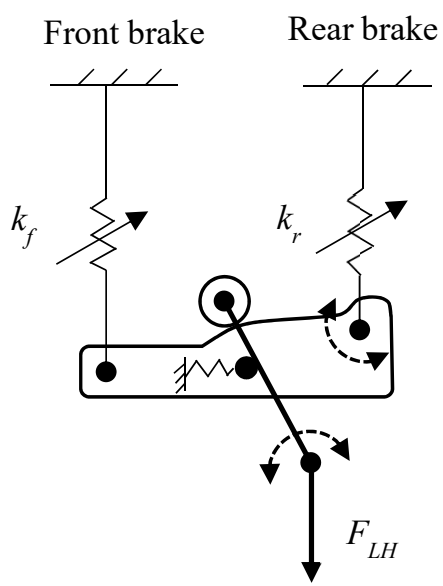

Figure 1. The concept of the variable combined system (VCBS).

In this mechanism, the cam profile and the returning spring's rate matching design are critical for the BFD design. The design process requires taking the equivalent stiffnesses 
of the front and rear brake systems into account since the difference between the displacements of the swingarm's two sides strongly affects the roller's balancing position on the cam surface. The cam synthesis procedure has been explored during the last years [7-9]. However, because the stiffnesses of the brake systems are highly nonlinear in nature, the relationship between the input force and the BFD ratio by the VCBS is quite complicated. It is challenging to apply the existing methods for the VCBS design directly. First, this paper derives a mathematical model coupling the VCBS mechanism with the brake system's equivalent stiffness and then proposes a parameter matching design method to resolve this difficulty. Both the simulation and experimental results show that the proposed method possesses the advantages of being feasible, easy to implement, and efficient in generating a cam profile to match the parameters of the VCBS. Road tests are carried out to verify the performance of the VCBS prototype designed by the developed method. Finally, the indexes for evaluating the VCBS's braking performance are discussed.

\section{The Mechanism of VCBS}

The VCBS is a force distributor that distributes the input force of the front and rear brake systems. The force distribution ratio of a VCBS (denoted by $R_{f}$ hereafter) is defined as, i.e.,

$$
R_{f}=\frac{F_{f}}{F_{f}+F_{r}}
$$

$F_{f}$ and $F_{r}$ in Equation (1) are the forces (N) distributed between the front and rear brake systems, respectively, by the VCBS. With the distributed force, the front and rear wheels generate respective braking forces expressed as:

$$
\begin{gathered}
F_{f w}=F R_{f} G_{f} E_{f}, \\
F_{r w}=F\left(1-R_{f}\right) G_{r} E_{r},
\end{gathered}
$$

where $F$ is the input force (N) to VCBS; $G_{f}$ and $G_{r}$ are the mechanical gains, and $E_{f}$ and $E_{r}$ are the efficiencies of front and rear brake systems, respectively. Efficiency includes transmitting and mechanical efficiencies. During braking, the maximum available brake forces provided by the front and rear tire-road contact patches, $F_{f \mu}$ and $F_{r \mu}$, are determined by $[10,11]$ :

$$
\begin{gathered}
F_{f \mu}=\frac{W}{L}\left(L_{r}+a h\right) \mu, \\
F_{r \mu}=\frac{W}{L}\left(L_{f}-a h\right) \mu,
\end{gathered}
$$

where $\mu$ is the road adhesion coefficient, $a$ the deceleration of the motorcycle in $g, W$ the motorcycle's weight $(\mathrm{N}), h$ the height $(\mathrm{m})$ of center gravity (C.G.), $L_{f}$ the distance $(\mathrm{m})$ from the C.G. to the front axle, and $L$ the wheelbase (m). From Equations (2)-(5), the actual braking forces produced by front and rear tire contact patches are:

$$
\begin{aligned}
& F_{f t}=\min \left(F_{f w}, F_{f \mu}\right), \\
& F_{r t}=\min \left(F_{r w}, F_{r \mu}\right) .
\end{aligned}
$$

The braking force distribution (BFD) ratio of the wheels $\left(R_{B F D}\right)$ of a motorcycle on braking is defined as:

$$
R_{B F D}=\frac{F_{f t}}{F_{f t}+F_{r t}} .
$$

For a road condition of $\mu$, the value of $R_{B F D}$ that makes the front and rear wheels lock simultaneously is referred to as the ideal $R_{B F D}$ in this paper. Since the amount of load being transferred increases with the increase of deceleration, the ideal $R_{B F D}$ is a function of the 
input force $F$ from the left handbrake lever. By letting $a=\mu, F_{f w}=F_{f \mu}$, and $F_{r w}=F_{r \mu}$ in Equations (2)-(5), the required $R_{f}$ (called $R_{f_{-} \text {ideal }}$ ) for a VCBS that achieves the ideal $R_{B F D}$ for a motorcycle can be calculated as:

$$
R_{f_{-} \text {ideal }}=\frac{W\left(-B+\sqrt{B^{2}-4 A C F}\right)}{2 A F\left(G_{f} E_{f}-G_{r} E_{r}\right)}-\frac{G_{r} E_{r}}{G_{f} E_{f}-G_{r} E_{r}}
$$

where $A=\frac{W h}{L}, B=W\left(\frac{L_{r}}{L}-\frac{G_{f} E_{f}}{G_{f} E_{f}-G_{r} E_{r}}\right)$ and $C=\frac{G_{f} E_{f} G_{r} E_{r}}{G_{f} E_{f}-G_{r} E_{r}}$. It is noted that the $R_{f_{-} \text {ideal }}$ in Equation (9) is determined under the condition of neglecting the effects of the motorcycle's suspension system. In practice, a VCBS is designed to have an $R_{f}$ slightly lower than $R_{f_{-} \text {ideal }}$ to account for the suspension system's effect and parametric uncertainties existing in the calculations. From Equation (9), the value of $R_{f_{-} \text {ideal }}$ varied widely with the input force. For example, the value of $R_{f_{-} \text {ideal }}$ varied from 0.32 to 0.78 on $F=0 \sim 700 \mathrm{~N}$ for the target motorcycle in this study. The design of the VCBS aimed to meet this requirement, that is, having a wide range of $R_{f}$ in response to variations of the input force $F$.

Figure 2 schematically shows the mechanism of the VCBS for motorcycles equipped with front disc and rear drum brake systems in detail. The main component of the VCBS is a swingarm with a contoured cam surface on its upper side. One side of the swingarm is connected to the rear brake wire through a pin that integrates the swingarm with roller $\mathrm{R}$ and link R. A bump on the bottom of the swingarm's left-hand side is designed to push the front brake's master cylinder piston. Link $C$ is swingable with one end pin-connected to link $\mathrm{LH}$ and roller $\mathrm{H}$, while its other end is pin-connected to roller $\mathrm{C}$. The input force $F$ from the left handbrake lever pulls link $C$ and then roller $C$ to act on the swingarm's cam surface.

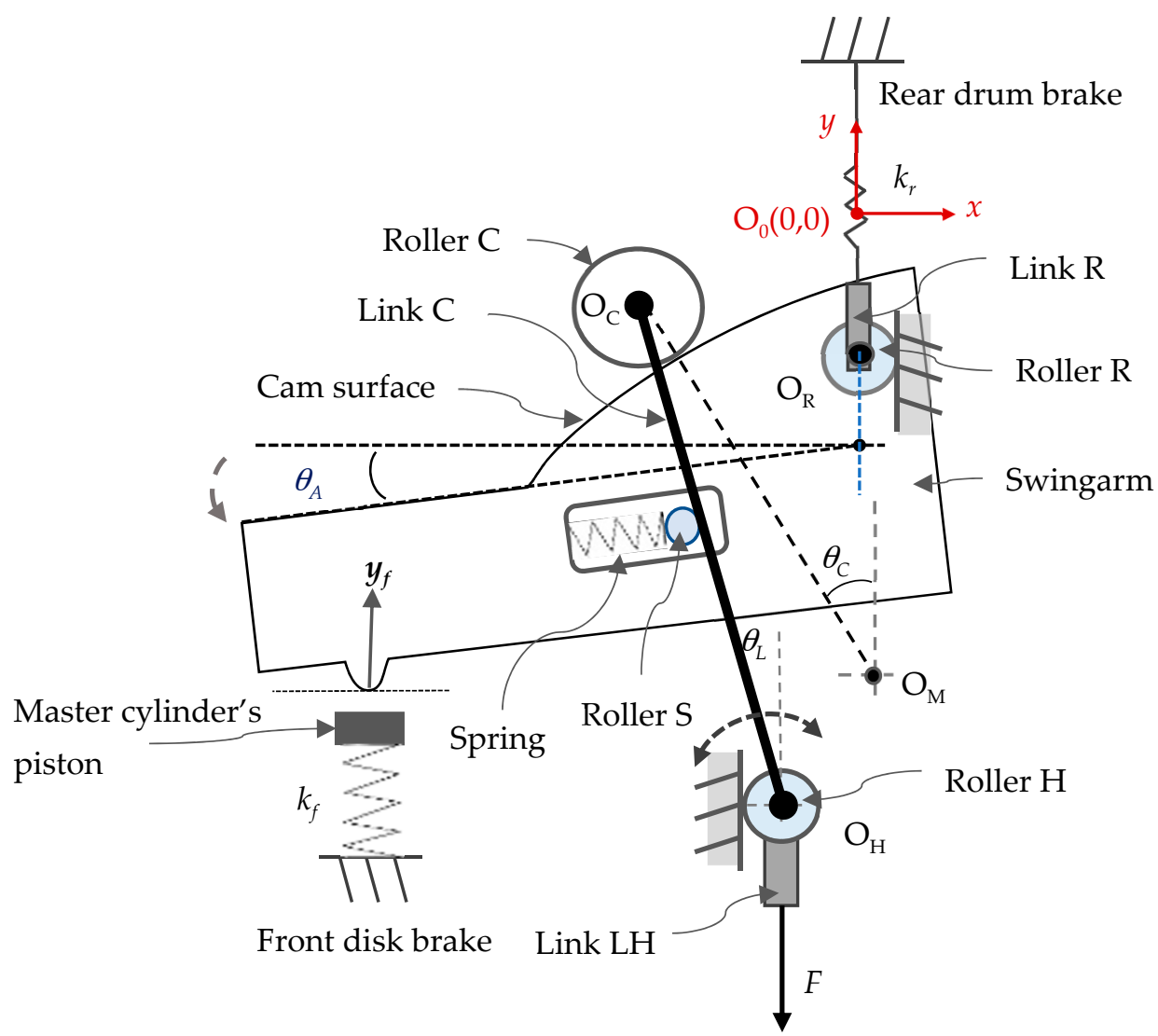

(a)

Figure 2. Cont. 


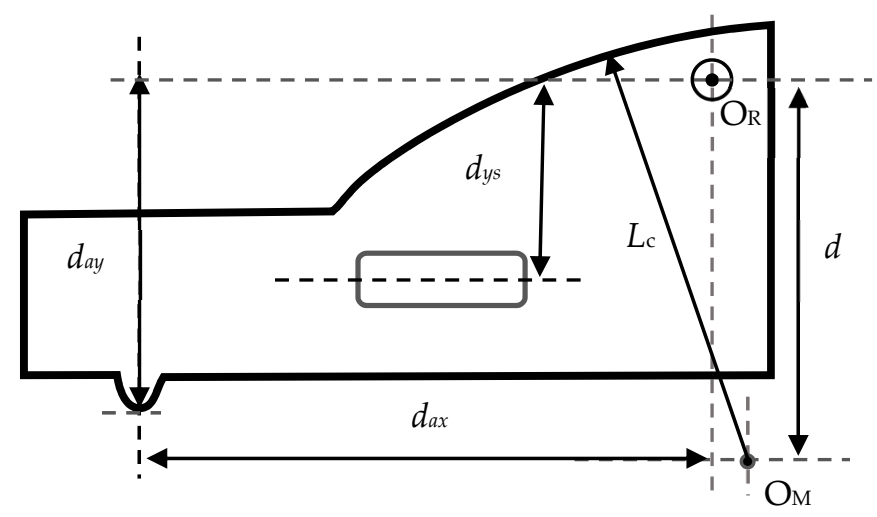

(b)

Figure 2. Schematic of the VCBS mechanism. (a) Schematic; (b) swingarm geometry.

Due to the cam profile, the input force $F$ acting on the roller $C$ generates a force component to move roller $\mathrm{C}$ along the cam surface to a balance position. Therefore, the position of $F^{\prime}$ s acting point can be varied to change the force distribution ratio $R_{f}$. To provide the required reacting forces for the movement of roller $\mathrm{C}$, rollers $\mathrm{H}$ and $\mathrm{R}$ are confined to slide on their respective guides on the mechanism's shell. A nonlinear returning spring mounted in the slot of the swingarm provides a balancing force against the movement of roller $\mathrm{C}$. In this mechanism, the cam profile and the returning spring's stiffness are the critical parameters for the braking forces distribution design.

\section{Mathematical Model}

For all the calculations hereafter, the origin $\mathrm{O}_{0}(0,0)$ is set at the initial position of roller $\mathrm{R}^{\prime}$ s center, and the weights of all the components in the system are neglected. With the braking forces of the front and rear brake systems $\left(F_{r}\right.$ and $\left.F_{f}\right)$ distributed by the VCBS, the master cylinder piston's stroke $y_{f}(\mathrm{~mm})$ and the rear brake cable's stroke $y_{r}(\mathrm{~mm})$ are determined by the equivalent spring rates $k_{f}$ and $k_{r}$ of the front and rear brake systems, respectively, i.e.,

$$
y_{r}=\frac{-F_{r}}{k_{r}}, \text { and } y_{f}=\frac{-F_{f}}{k_{f}},
$$

where $k_{f}$ and $k_{r}(\mathrm{~N} / \mathrm{mm})$ are measured from the brake systems of the target motorcycle. The stroke difference between the two sides of the swingarm results in the swingarm's rotating angle $\theta_{A}(\mathrm{rad})$ of:

$$
\theta_{A}=\tan ^{-1}\left(\frac{y_{r}-y_{f}}{d_{a x}}\right)
$$

where $d_{a x}$ is the horizontal distance $(\mathrm{mm})$ between the two force acting points of the swingarm, as shown in Figure 2b.

The cam surface on the swingarm is designed with a variable radius of $L_{c}$ centered at $\mathrm{O}_{\mathrm{M}}\left(x_{m}, y_{m}\right)$. According to the geometry of the swingarm shown in Figures $2 \mathrm{~b}$ and 3 , the following relationship can be derived as:

$$
L_{h} \sin \theta_{L}-L_{c r} \sin \theta_{C}+d \sin \theta_{A}-x_{h}=0,
$$

where $L_{c r}=L_{c}+r_{c} . r_{c}$ is the radius $(\mathrm{mm})$ of roller $\mathrm{C} ; d$ is the distance $(\mathrm{mm})$ between $\mathrm{O}_{\mathrm{M}}\left(x_{m}, y_{m}\right)$ and $\mathrm{O}_{\mathrm{R}}\left(x_{r}, y_{r}\right) ; x_{h}$ is the horizontal position $(\mathrm{mm})$ of roller $\mathrm{H}$; and $L_{h}$ is the length $(\mathrm{mm})$ of link $C$. The variable $\theta_{L}$ is the swing angle (rad) of link $C ; \theta_{C}$ is the angle (rad) between the $y$ axis and the line connected by $\mathrm{O}_{\mathrm{C}}\left(x_{c}, y_{c}\right)$ and $\mathrm{O}_{\mathrm{M}}\left(x_{m}, y_{m}\right)$. For the 
returning spring, a variable pitch spring [12] that realizes the nonlinear hardening spring characteristics is applied in this study to provide the spring force $F_{s}$ expressed as:

$$
F_{s}=k_{s 1}\left(d_{s}-s_{0}\right)+k_{s 2}\left(d_{s}-s_{0}\right)^{3},
$$

where $k_{s 1}(\mathrm{~N} / \mathrm{mm})$ and $k_{s 2}\left(\mathrm{~N} / \mathrm{mm}^{3}\right)$ are the spring rates. The variables $s_{0}$ and $d_{s}$ are the distances $(\mathrm{mm})$ from the center $\mathrm{O}_{\mathrm{R}}$ to spring's free end and roller $\mathrm{S}^{\prime} \mathrm{s}$ location, respectively, measured along the returning spring's axis. In the design stage, the value of $s_{0}$ is given to determine the pre-stressed deformation of the spring, and $d_{s}$ is calculated as:

$$
d_{s}=\left(d-d_{y s}\right) \tan \theta_{C A}+\left(L_{c r}-\frac{d-d_{y s}}{\cos \theta_{c A}}\right) \frac{\sin \theta_{C L}}{\cos \theta_{L A}},
$$

where $\theta_{C A}=\theta_{C}-\theta_{A}, \theta_{L A}=\theta_{L}-\theta_{A}, \theta_{C L}=\theta_{C}-\theta_{L}$. The variable $d_{y s}$ is the orthogonal distance $(\mathrm{mm})$ between the returning spring's axis and the center $\mathrm{O}_{\mathrm{R}}$.

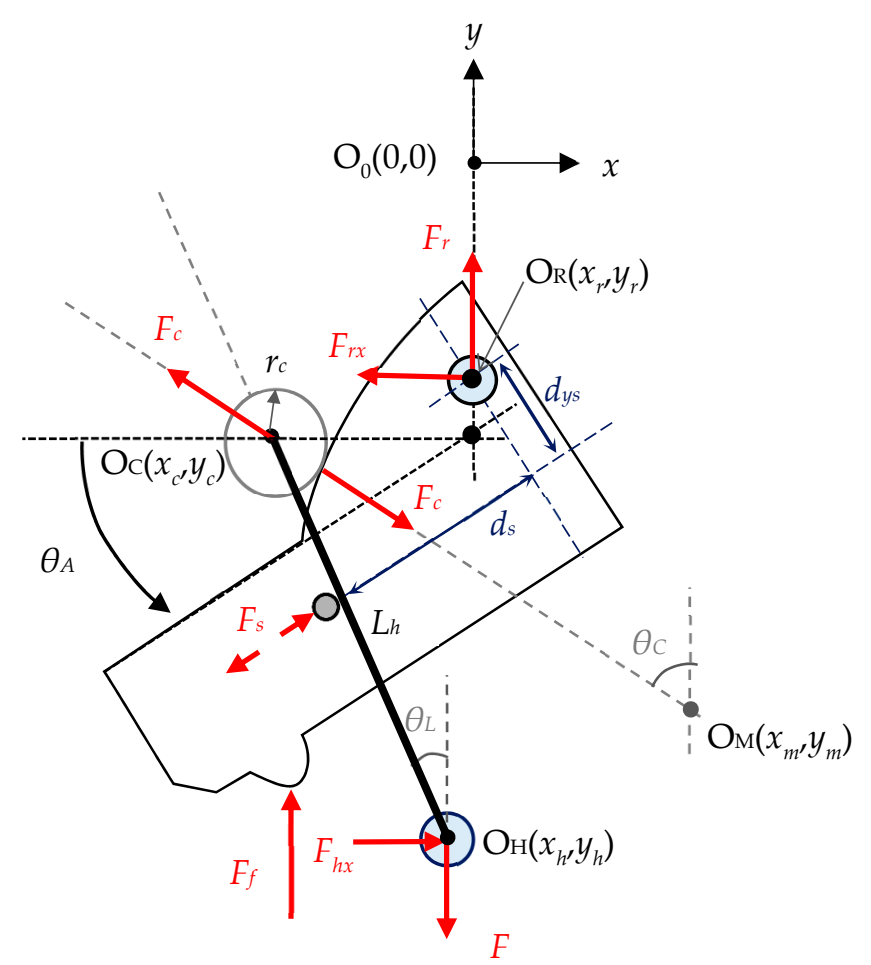

Figure 3. Free body diagram of link $C$ and the swingarm.

As shown in Figure 3, the application of input force $F$ makes roller $C$ generate a normal force, $F_{c}$, acting on the cam surface in the form of

$$
F_{c}=\frac{F \cos \theta_{L A} \sin \theta_{L}-F_{s}}{\cos \theta_{c} \cos \theta_{L A} \sin \theta_{L}} .
$$

By taking the moment about $\mathrm{O}_{\mathrm{H}}$ of link C's free body diagram in Figure 3, the relations among $F_{c}, F_{S}, \theta_{A}, \theta_{L}$, and $\theta_{C}$ can be obtained as:

$$
F_{c} L_{h} \sin \theta_{C A}-F_{s} L_{s h} / \cos \theta_{L A}=0,
$$

where $L_{s h}$ is the distance $(\mathrm{mm})$ between rollers $\mathrm{S}$ and $\mathrm{H}$, which is calculated as:

$$
L_{s h}=L_{h}-\left(L_{c r}-\frac{d-d_{y s}}{\cos \theta_{c A}}\right) \frac{\cos \theta_{C A}}{\cos \theta_{L A}} .
$$


Finally, the respective force distributed between the front and rear brakes can be determined by taking the moment about the center $\mathrm{O}_{\mathrm{R}}$ using the free body diagram of the swingarm shown in Figure 3:

$$
\begin{gathered}
-F_{c} d \sin \theta_{C A}+F_{s}\left(d_{y s}-d_{s} \tan \theta_{L A}\right)+F_{f} d_{a x} \cos \theta_{A}=0, \\
F_{r}=F-F_{f} .
\end{gathered}
$$

\section{Parameter Matching Design}

Once the mechanical design of the VCBS has been finished, an optimal $R_{f}$ curve for a target motorcycle can be obtained (or tuned) by designing a cam profile to match the returning spring's stiffness $\left(k_{\mathrm{s} 1}, k_{\mathrm{s} 2}\right)$. Thus, a method to generate an optimal cam profile to match the existing VCBS's parameters is required. The cam profile of the swingarm is a curve centered at $\mathrm{O}_{\mathrm{M}}\left(x_{m}, y_{m}\right)$ with its radius, $L_{c}$, varied with the angle difference $\theta_{C A}$. Since the system that combined the VCBS model and the brake system's stiffness is complicated and highly nonlinear, it is difficult to directly apply the existing methods of cam profile design. A method that applies the direct one-step-ahead adaptive control technique $[13,14]$ is proposed to solve this problem.

For specific values of the spring rates $k_{\mathrm{s} 1}$ and $k_{\mathrm{s} 2}$, the proposed optimal $L_{\mathrm{c}}$ design is proceeded by building a surrogate model to capture the local behavior of $R_{f}$ for $F=0 \sim 700 \mathrm{~N}$. This method, called metamodeling, has been widely used in engineering applications. The surrogate model is used to represent the actual model to reduce computational cost. Extensive research has been carried out to generate the surrogate models based on limited samples $[15,16]$. In this study, a surrogate model is selected to represent the original system (the VCBS model coupled with the brake system's stiffness):

$$
R_{f}(k)=x(k-1)^{T} \theta(k-1) .
$$

with

$$
\begin{gathered}
\theta(k)=\left[\begin{array}{lll}
c_{1}(k) & c_{2}(k) & c_{3}(k)
\end{array}\right]^{T}, \\
x(k)=\left[\begin{array}{ccc}
\cos \theta_{L}(k) & \cos \theta_{C A}(k) \log L_{c}(k) & \frac{F(k)}{\cos \theta_{C A}(k)}
\end{array}\right]^{T},-\frac{\pi}{2}<\theta_{C A}<\frac{\pi}{2}
\end{gathered}
$$

where $F(k)$ is the discretized input force that takes values $k=1,2,3, \ldots$, i.e., $F(k)=k \Delta F$ with $\Delta F$, the sampling value of $F$. In control words, the original system can be considered as locally differentially flat since the system's output $R_{f}(k)$ is visible from its state, $\theta_{L}(k)$ and $\theta_{C A}(k)$, and the input $F(k)$ is visible using Equation (20). Flat systems are useful in nonlinear control engineering for explicit trajectory tracking applications. Once the behavior of the flat system can be given by the flat output, planning trajectories in output space and then mapping them to the appropriate inputs are possible; please see [17] for details. The coefficients in Equation (21) can be estimated online using the Kalman estimator [18] or the least-squares estimator $[19,20]$. Because the system is free from noise, the sequential least-squares estimator [21] is applied as follows:

$$
\begin{gathered}
\hat{R}_{f_{-} L c 0}(k)=x^{T}(k) \hat{\theta}(k-1), \\
\varepsilon(k)=R_{f_{-L c 0}}(k)-\hat{R}_{f_{-} L 0}(k), \\
\gamma(k)=\frac{1}{\lambda+x^{T}(k) P(k-1) x(k)} P(k-1) x(k), \\
P(k)=\frac{1}{\lambda}\left[I-\gamma(k) x^{T}(k)\right] P(k-1), \\
\hat{\theta}(k)=\hat{\theta}(k-1)+\gamma(k) \varepsilon(k),
\end{gathered}
$$

where $\hat{\theta}(k)$ is the estimate of $\theta(k), \varepsilon(k)$ the prediction error, $P(k)$ the covariance matrix, and $\lambda$ the forgetting factor. Initially, $\hat{\theta}(0)$ is set arbitrarily, and $P(0)=\alpha I_{3 \times 3}$. A large $\alpha$ tends to be the high correction of $\hat{\theta}$ and therefore tends towards fast convergence. The forgetting factor is in the range of $0.9 \leq \lambda \leq 1$; a large $\lambda$ behaves with high robustness against disturbance; 
on the other hand, a small $\lambda$ behaves with fast-tracking capability. In this study, $\alpha=1000$ and $\lambda=0.95$ are chosen.

We define the reference model that specifies the ideal response of Equation (20) to the target value $R_{f}^{*}(k)$ as:

$$
R_{m}(k+1)=a_{m} R_{m}(k)+b_{m} R_{f}^{*}(k), R_{m}(1)=R_{m 0},
$$

where $R_{m}$ is the reference model's output. Since the desired $R_{f}$ curve is expected to have a pattern similar to $R_{f_{-} \text {ideal, }}$ the input to the reference model $R_{f}^{*}(k)$ is defined as

$$
R_{f}^{*}(k)=R_{f \_ \text {ideal }}(k)-R_{f 0},
$$

where $R_{f 0}$ is a constant used to make the resulting $R_{f}$ curve slightly lower than $R_{f_{-} i d e a l}$, as mentioned previously. We define the tracking error between the reference model output $R_{m}(k)$ and the $\hat{R}_{f_{-} n e w}(k)$ estimated by the surrogate model using the newly designed cam profile, $L_{\mathcal{C}_{-} \text {new }}(k)$, as

$$
e(k)=\hat{R}_{f_{-} \text {new }}(k)-R_{m}(k) .
$$

The problem is thus to design a controller with output $L_{c}(k)$ to make the plant output $\hat{R}_{f \_n e w}(k+1)$ track the reference model output $R_{m}(k+1)$. We define the desired tracking error dynamics as:

$$
e(k+1)+k_{p} e(k)=0,
$$

where $\left|k_{p}\right| \leq 1$ is selected to determine the error convergence rate. Using Equations (20)-(22) and (26), the left-hand side of Equation (27) can be rewritten as:

$$
\begin{gathered}
e(k+1)+k_{p} e(k)= \\
k_{p} e(k)-R_{m}(k+1)+\hat{c}_{1} \cos \theta_{L}(k)+\hat{c}_{2} \cos \theta_{C A}(k) \log L_{c}(k)+\hat{c}_{3} F(k) / \cos \theta_{C A}(k), \\
-\frac{\pi}{2}<\theta_{C A}(k)<\frac{\pi}{2} .
\end{gathered}
$$

Let the right-hand side of Equation (28) be zero to meet the requirement of Equation (27), a new sequence of $L_{\mathrm{c}}(k)$ can be obtained and expressed as:

$$
L_{C \_n e w}(k)=e^{\frac{R_{m}(k+1)-k p e(k)-\hat{c}_{1} \cos \theta_{L}(k)-\hat{c}_{3} F(k) / \cos \theta_{C A}(k)}{\hat{c}_{2} \cos \theta_{C A}(k)}},-\frac{\pi}{2}<\theta_{C A}(k)<\frac{\pi}{2} .
$$

Equation (29) is the adaptive law that generates $L_{\text {c_new }}(k)$ to make $\hat{R}_{f \_n e w}(k+1)$ converge to $R_{m}(k+1)$, based on the data at instant $k$.

Remark 1. In Equation (28), the convergence of the tracking error e( $k$ ) is guaranteed by selecting $\left|k_{p}\right| \leq 1$ and $L_{\mathcal{C}_{-} \text {new }}$ in the form of Equation (29), provided that $L_{\mathcal{C}_{-} n e w}$ is bounded. The boundness of $L_{c_{-} n e w}$ is ensured when $-\pi / 2<\theta_{C A}<\pi / 2$ holds. Because of the designed geometrical dimensions of the VCBS in this study, the operation range of $\theta_{C A}$ is within $0<\theta_{C A}<1$ for the target range of $R_{f}$ within $0 \leq R_{f} \leq 0.6$, implying that the boundness of $L_{c_{-} n e w}(k)$ is guaranteed automatically.

The procedure for designing the swingarm's cam profile is summarized in Figure 4. Before starting the design, vehicle parameters such as the center of gravity, mechanical gains and efficiencies, and equivalent stiffness of the brake systems have to be measured. The equivalent brake systems' stiffnesses are expressed as:

$$
\begin{aligned}
& k_{f}=a_{1} F_{f}^{2}+a_{2} F_{f}+a_{3}, \\
& k_{r}=b_{1} F_{r}^{2}+b_{2} F_{r}+b_{3} .
\end{aligned}
$$




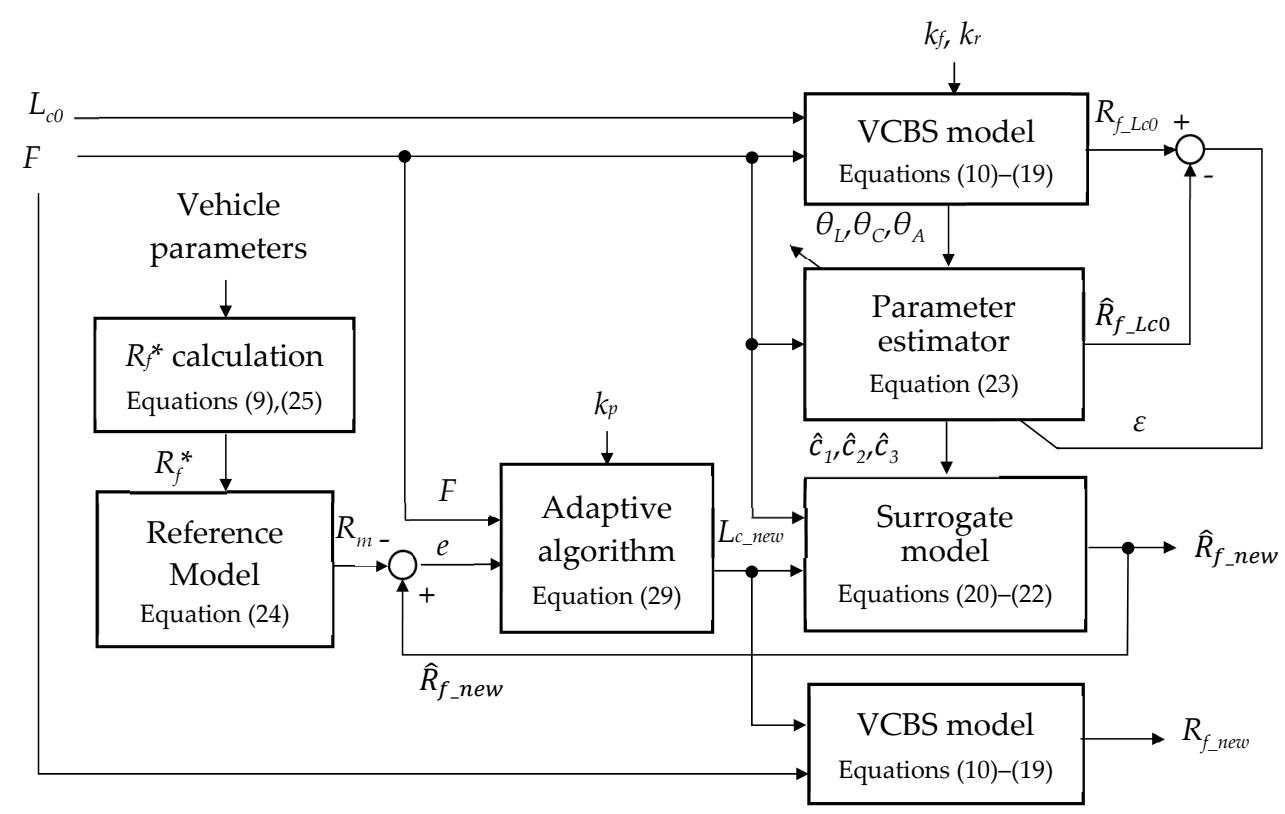

Figure 4. Block diagram for the cam profile design.

It is noticed that $k_{f}$ represents the relationship between the master cylinder piston's resisting force $F_{f}(\mathrm{~N})$ and stroke $y_{f}(\mathrm{~mm})$, while $k_{r}$ is the relationship between the rear-brake wire's resisting force $F_{r}$ and displacement $y_{r}$. After the $k_{f}$ and $k_{r}$ have been calculated from the measured data, they are expressed as functions of the resisting forces for further calculations. The coefficients in Equations (30) and (31) are obtained through curve fitting. For the target motorcycle in this paper, the coefficients are obtained as: $a_{1}=-0.0006571$, $a_{2}=0.143$, and $a_{3}=1.012 ;$ and $b_{1}=0.0006017, b_{2}=0.01$, and $b_{3}=3.633$.

The target $R_{f}$ curve (denoted by $R_{f}{ }^{*}$ ) is calculated based on vehicle's parameters and the required braking performance. After finishing a VCBS's mechanical design, its geometrical parameters are used to construct the VCBS model of Equations (10)-(19). The cam profile design corresponding to a selected spring rate combination of $k_{\mathrm{s} 1}$ and $k_{\mathrm{s} 2}$ of Equation (13) is started by giving an initial profile of a constant radius of $L_{c 0}$. The simulation of the VCBS model generates the $R_{f}$ curve corresponding to the $L_{c 0}$ (called $R_{f_{-} L c 0}$ ). Based on the curve $R_{f_{-} L c 0}$, the online parameter estimator of Equation (23) estimates the parameters $\hat{\theta}(k)$ of Equation (21). The adaptive law of Equation (29) generates the sequence $L_{c_{-} \text {new }}(k)$ that makes the tracking error $e(k)$ converge in the case of Equation (27). The sequence $L_{c_{-} \text {new }}(k)$ is a function of $\theta_{C A}$, which is used to fabricate the cam profile. For this purpose, an equation is used to represent the cam profile expressed as:

$$
L_{\mathcal{C}_{n} \text { new }}=b_{1}+b_{2} / \log \theta_{C A}+b_{3} /\left(\log \theta_{C A}\right)^{5}, 0<\theta_{C A}<1,
$$

where $b_{1} \sim b_{3}$ are obtained through curve fitting using the sequence $L_{c_{-} \text {new }}(k)$. A design example is demonstrated here by using the parameters of the target motorcycle and VCBS model listed in Table 1. The parameters for the adaptive law are selected as $k_{p}=0.5$, $R_{m 0}=-0.3, R_{f 0}=0.1, a_{m}=0.96$, and $b_{m}=0.04$. The spring rates are $k_{s 1}=8 \mathrm{~N} / \mathrm{mm}$ and $k_{s 2}=0.08 \mathrm{~N} / \mathrm{mm}^{3}$. The original cam profile used for the design basis has a constant radius of $L_{c 0}=22 \mathrm{~mm}$. 
Table 1. Parameters for simulations.

\begin{tabular}{lc}
\hline Vehicle Parameters & Value \\
\hline Laden weight, $W(\mathrm{~N})$ & 2589.8 \\
Wheelbase, $L(\mathrm{~m})$ & 1.205 \\
Height of gravity center, $h(\mathrm{~m})$ & 0.77 \\
\hline Front brake system & \\
Mechanical gain, $G_{f}$ & 4.124 \\
Efficiency of disk brake system, $E_{f}$ & 0.801 \\
\hline Rear brake system & \\
Mechanical gain, $G_{r}$ & 3.30 \\
Efficiency of drum brake system, $E_{r}$ & 0.7055 \\
\hline VCBS parameters $($ see Figure 1$)$ & \\
Distance between spring axis and $\mathrm{O}_{\mathrm{R}}, d_{y s}(\mathrm{~mm})$ & 6 \\
$x$ coordinate of $\mathrm{O}_{\mathrm{H}}, x_{h}(\mathrm{~mm})$ & -4 \\
Swingarm's horizontal active length, $d_{a x}(\mathrm{~mm})$ & 25 \\
Distance between $\mathrm{O}_{\mathrm{M}}$ and $\mathrm{O}_{\mathrm{R}}, d(\mathrm{~mm})$ & 19.5 \\
Radius of roller $C_{1}, r_{c}(\mathrm{~mm})$ & 3.5 \\
Length of link $C, L_{h}(\mathrm{~mm})$ & 36 \\
Distance from $\mathrm{O}_{\mathrm{R}}$ to spring's end at free length status, $s_{0}(\mathrm{~mm})$ & -3 \\
\hline
\end{tabular}

The convergence of the identification procedure is illustrated in Figures 5 and 6. Figure 5 presents the relationship between the trace of $R_{f-L c 0}$ simulated by the VCBS model and the trace of $\hat{R}_{f_{-} L c 0}$ predicted by Equations (20)-(22) using the online estimated parameter $\hat{\theta}$. It can be seen that the predicted output of the surrogate model converges with the VCBS model well. On the other hand, comparing the traces of $R_{m}, R_{f}^{*}, R_{f_{-} \text {new }}$, and $R_{f_{-} L c 0}$ in Figure 6a shows that $R_{f_{-} L c 0}$ deviates from $R_{m}$ significantly, while the trace of $R_{f_{-} n \text { ew }}$ tracks the $R_{m}$ curve well, with the converged tracking error shown in Figure $6 \mathrm{~b}$. Here, the initial value $R_{m 0}$ in Equation (24) is selected to be negative in order to have small values of $R_{f_{-} \text {new }}$ corresponding to small values of $F$.

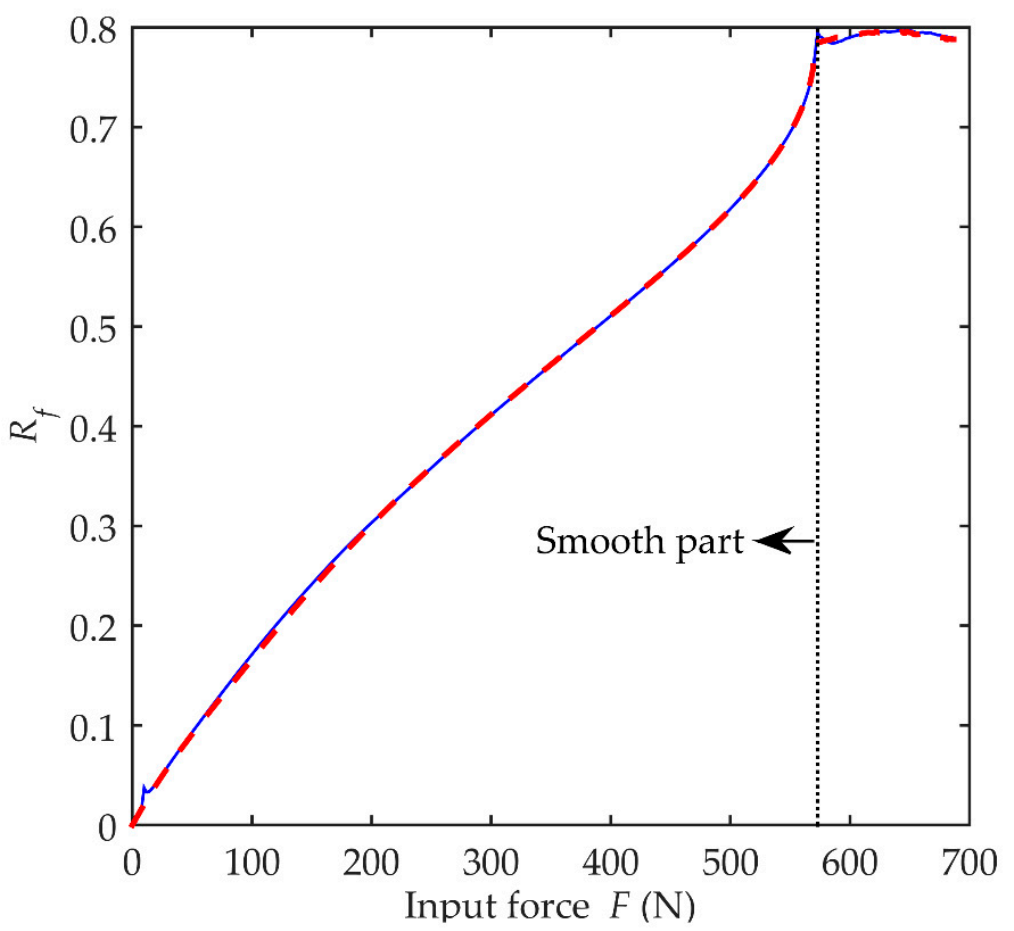

Figure 5. The trace of $R_{f-L c 0}$ (solid blue line) simulated by the VCBS model, and the trace of $\hat{R}_{f_{-} L c 0}$ (red dashed line) predicted by the surrogate model. 


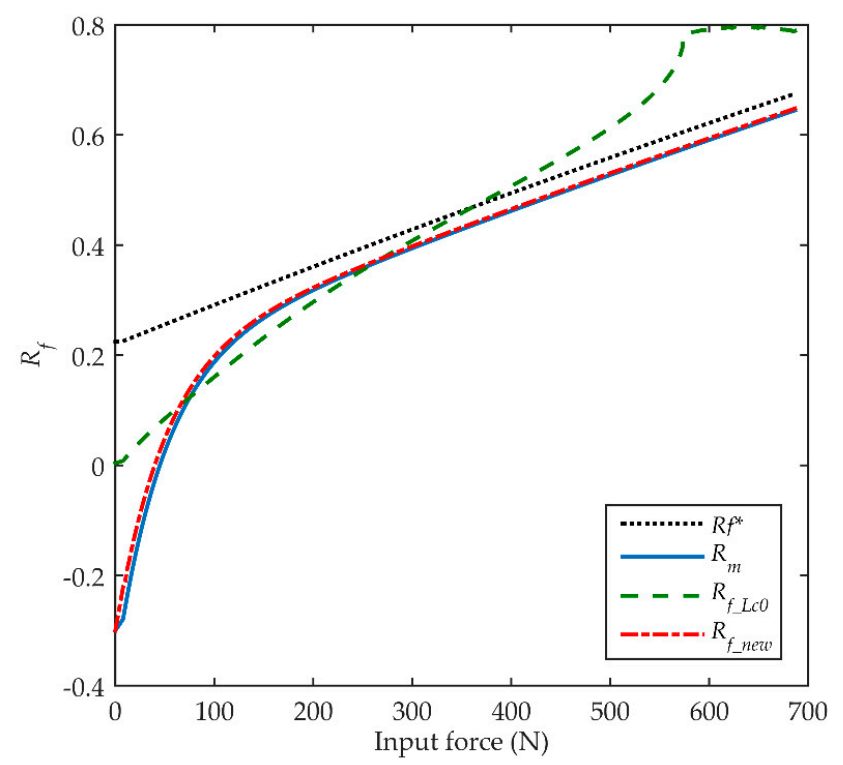

(a)

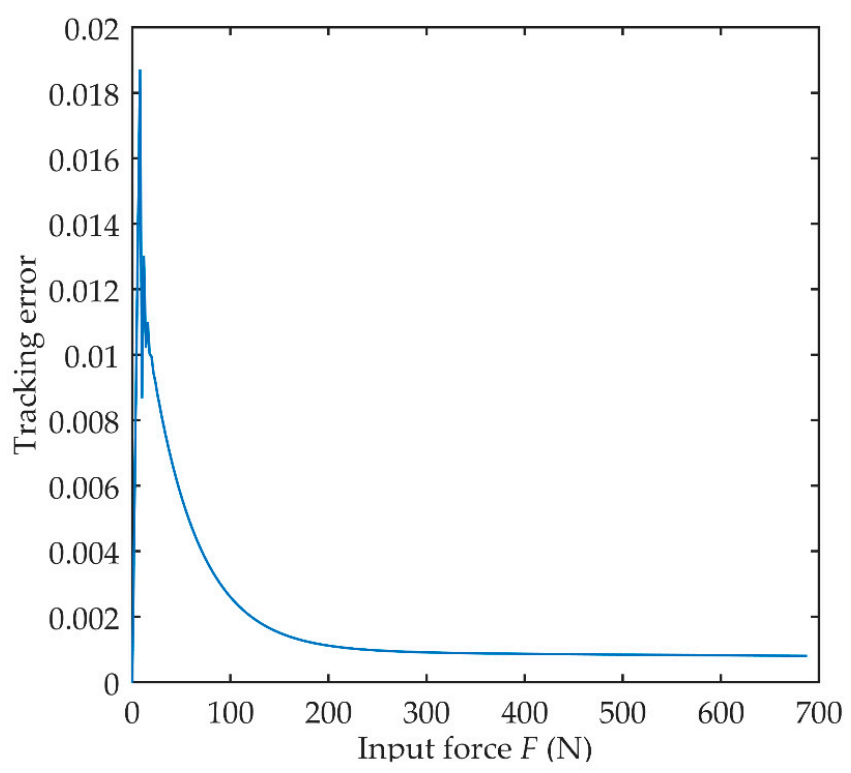

(b)

Figure 6. The design result: (a) comparison of the traces of $R_{f}{ }^{*}, R_{m}, R_{f-n e w}$, and $R_{f-L c 0} ;(\mathbf{b})$ the tracking error between $R_{m}$ and $R_{f_{-} \text {new }}$.

It is noticed that singularities may exist in Equations (14)-(17) for large values of $F$ depending on the designed parameters of the VCBS. When this happens, a discontinuity followed by an unsmooth sequence can appear on the $R_{f-L c 0}$ sequence. Since the smooth part of the $R_{f-L c 0}$ sequence spans the entire reasonable operation range of $\theta_{C A}$, it is sufficient for generating a satisfactory new cam profile. Therefore, only the smooth part of the $R_{f-L c 0}$ is utilized to generate the new cam profile in the design procedure, and the sequence after the discontinuity is discarded. For the present example, the simulation results show that the singularity presents around $\theta_{C A}=0.945$ (rad).

The effect of the newly designed cam profile is shown in Figure 7 . In this figure, the trajectory of dimensionless braking forces $F_{r t} / W$ and $F_{f t} / W$, varied with the increase of $F$, is defined as the braking force distribution curve (called BFD curve). This curve is useful for evaluating the performance of the VCBS because it can explore the relationship between the variation of decelerations and the force distribution ratio. In this diagram, the ideal 
BFD curve represents the traces of $F_{r t} / W$ and $F_{f t} / W$ that make the front and rear wheels locked simultaneously in all road conditions defined by $\mu$. It can be seen that the original cam profile $\left(L_{c 0}\right)$ generates a BFD curve that falls below the ideal BFD curve on large input forces. This situation is undesirable because it may cause the front wheel to lock first and consequently cause rollover accidents on large braking forces. The BFD curve generated by the newly designed cam profile $\left(L_{c_{-} \text {new }}\right.$ ) is successfully pulled above the ideal BFD curve for large $F$ values and has the same changing trend as the ideal BFD. The front braking force distribution ratio varies smoothly with the increase of $F$ and achieves a high value for large input forces. The improvement of the BFD curve can be understood by observing the two cam profiles on the $x-y$ coordinate shown in Figure 8. At the positions far from the profile's center, corresponding to large values of $\theta_{\mathrm{CA}}$ (so as to large values of $F$ ), $L_{c_{-} \text {new }}$ is increased gradually compared to $L_{c 0}$ and thereby pulls up the BFD curve.

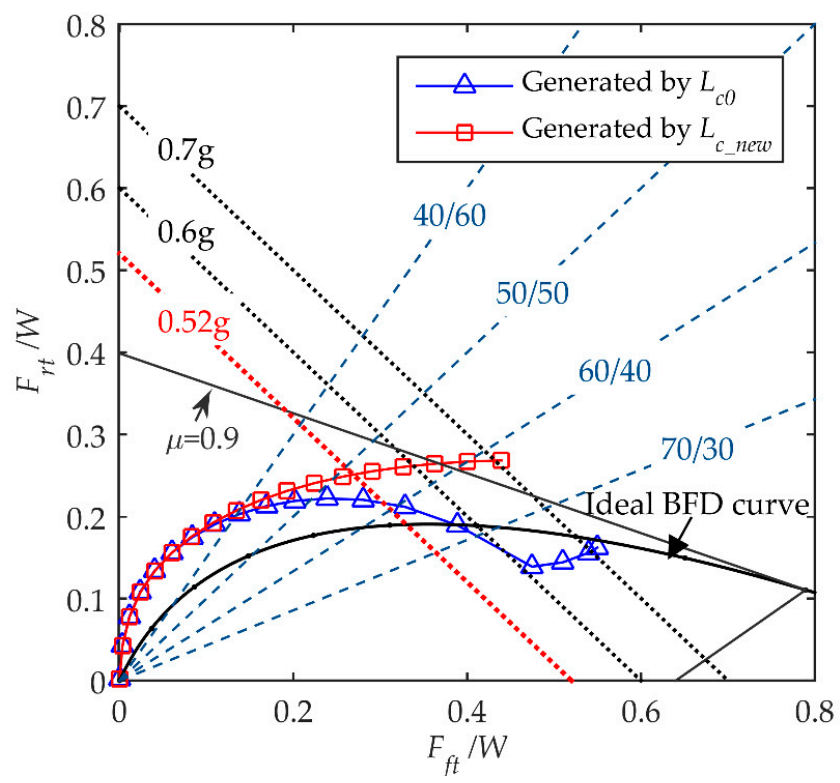

Figure 7. Comparison of the braking force distribution (BFD) curve using the original cam profile with that using the newly designed cam profile.

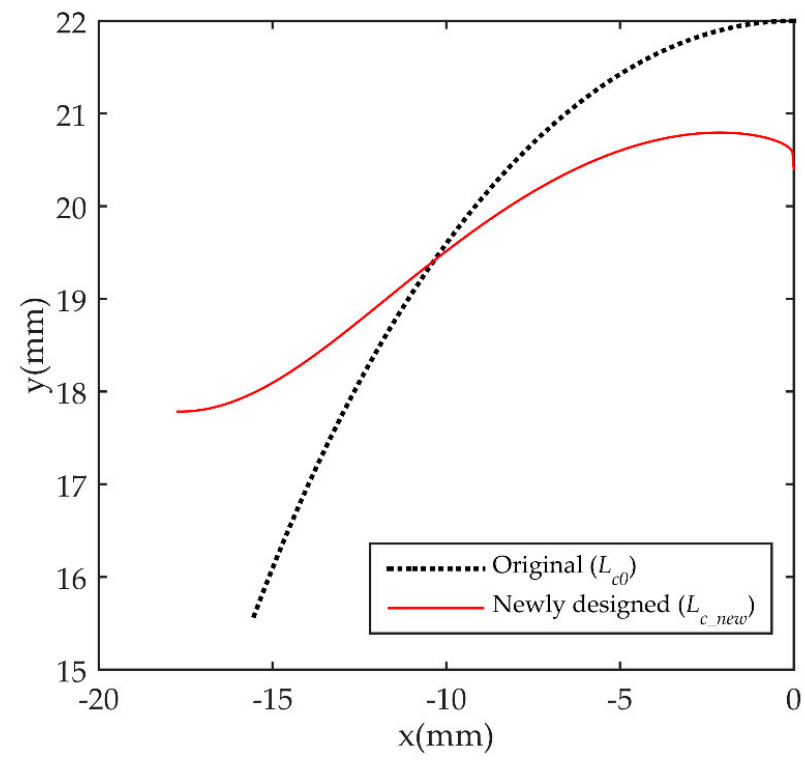

Figure 8. The newly designed cam profile $L_{\mathcal{C} \_n_{-} w}$ and the original cam profile $L_{c 0}$ on $x-y$ coordinates. 
The newly designed cam profile can match various spring rates to obtain different BFD curves. Figure 9 presents variations of the BFD curve for different spring rates. As shown in Figure 9a, increases in the linear spring rate $k_{s 1}$ move the overall BFD curve higher than the ideal BFD curve. On the other hand, the nonlinear spring rate $k_{s 2}$ affects the curvature of the BFD curve. When $k_{s 2}$ is increased, part of the BFD curve corresponding to high input forces is turned away from the ideal BFD curve, as shown in Figure $9 \mathrm{~b}$.

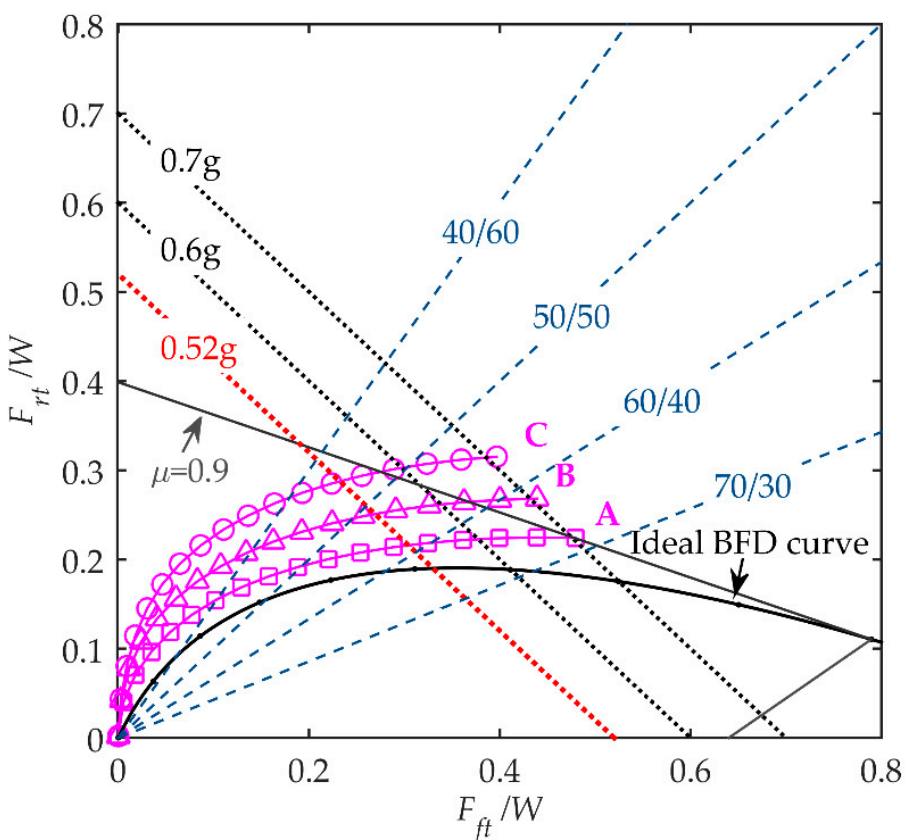

(a)

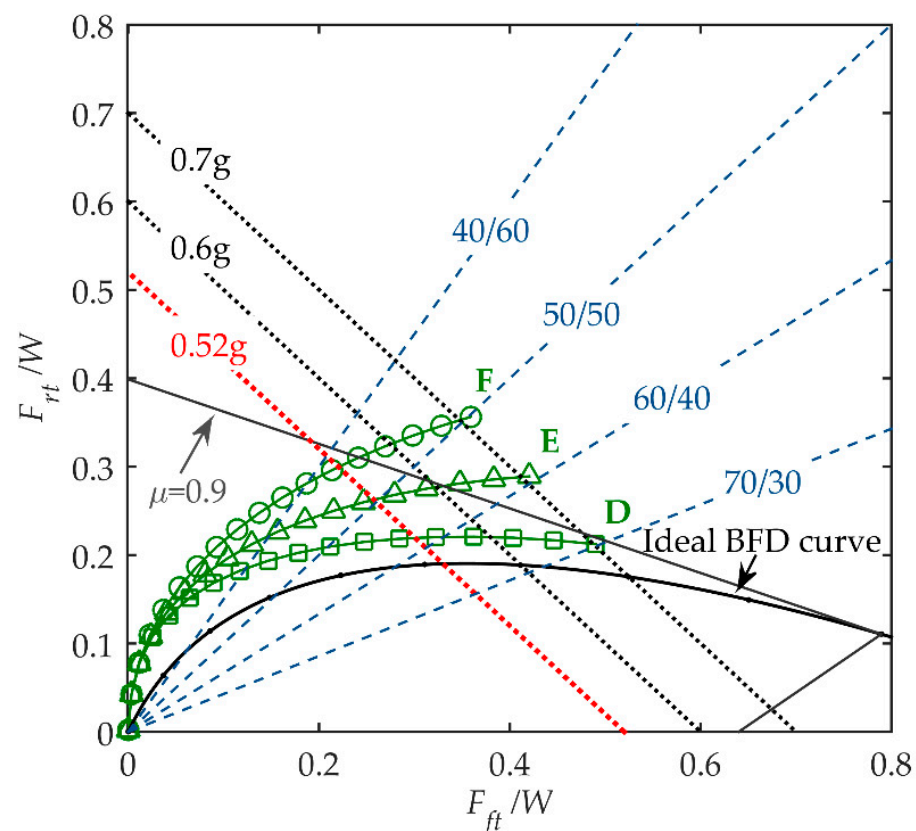

(b)

Figure 9. The BFD curves of different spring rates matching with the new designed cam profile. (a) Curves A C: $k_{s 1}=4,8,12 \mathrm{~N} / \mathrm{mm}$ with $k_{s 2}=0.08 \mathrm{~N} / \mathrm{mm}^{3}$; (b) curves D F: $k_{\mathrm{s} 2}=0.06,0.09$, $0.14 \mathrm{~N} / \mathrm{mm}^{3}$ with $k_{s 1}=8 \mathrm{~N} / \mathrm{mm}$. 


\section{Design Realization and Road Test Results}

A prototype of the VCBS has been designed and developed based on the design method described in the previous sections. Figure 10a shows the layout of the VCBS on a motorcycle with a $125 \mathrm{cc}$ gasoline engine and a disc-drum brake system. The input force to the VCBS is from the left handbrake lever through a braking wire, which is the primary source of the motorcycle's braking force. The right handbrake lever independently activates the front brake by pulling the master cylinder's piston through a wire. It is only for auxiliary or backup purposes. The prototype's photo is also presented in Figure 10b, in which the mechanism's cover is removed for clarity.

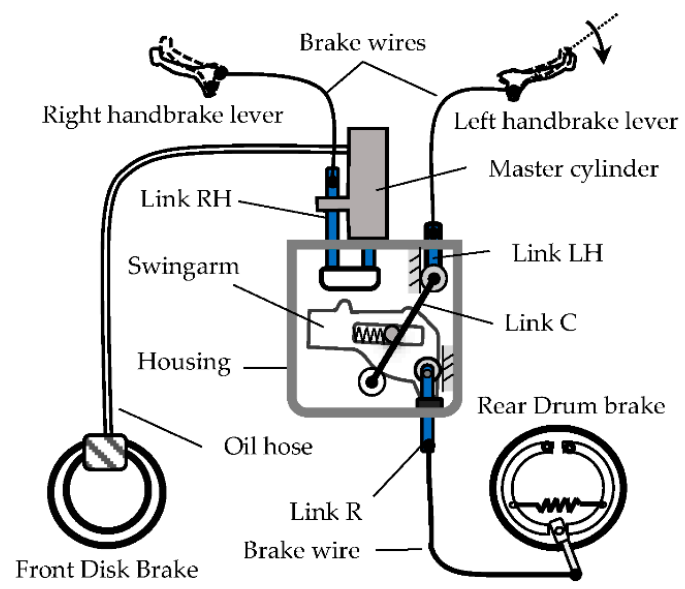

(a)

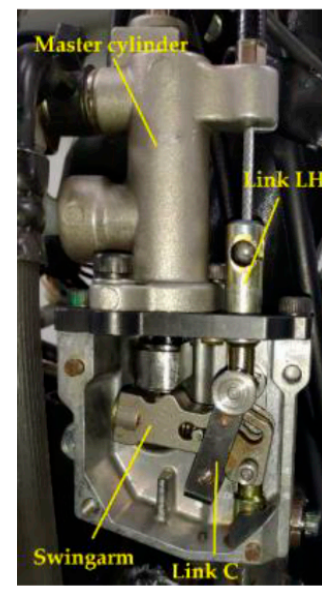

(b)

Figure 10. The layout of the VCBS prototype and the associated measurement system: (a) schematic; (b) photograph of the VCBS.

An auxiliary pin mounted onto link $C$ and a slot on the swingarm are designed, as shown in Figure 11, to achieve a higher deceleration on failure mode operations. The geometry of the slot is well designed so that the following two operation conditions hold:

(1) $\theta_{A} \geq \theta_{t h}>0$ : the swingarm and link $C$ locked together by the pin, where $\theta_{t h}$ is the maximum allowable anticlockwise rotating angle of the swingarm.

(2) $\theta_{A}<\theta_{t h}$ : the pin without contact with the boundary of the slot.

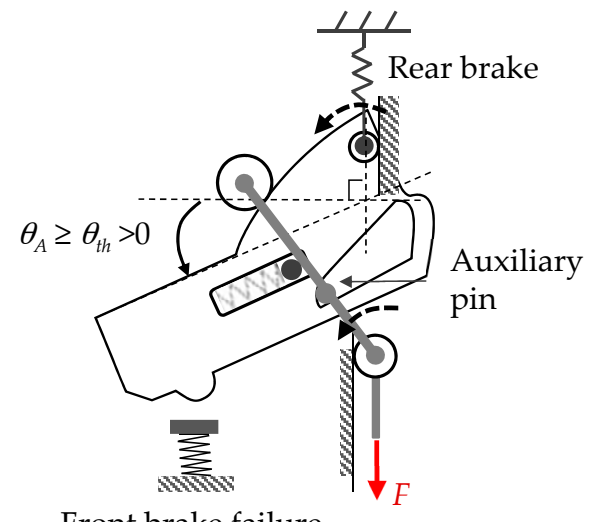

Front brake failure

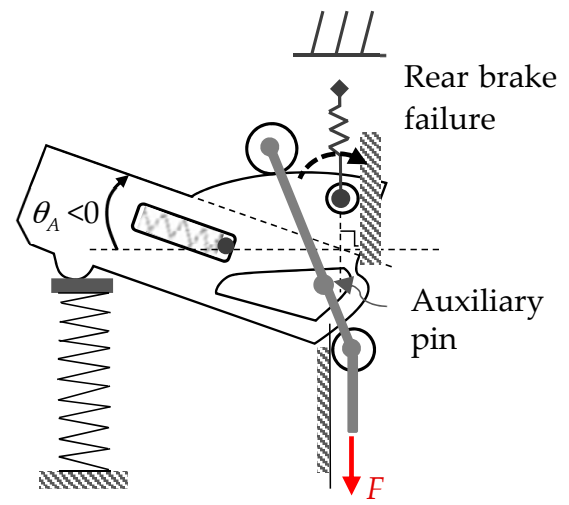

Front brake

(a)

(b)

Figure 11. Schematic of failure mode operations. (a) swingarm and link $C$ locked together when front brake failure occurs for $\theta_{A} \geq \theta_{t h}>0$; (b) swingarm rotates freely with rear brake failure $\theta_{A}<0$. 
The first condition is for front brake failure mode. When the master cylinder piston loses its resisting force against the swingarm because of front brake failure, its anticlockwise rotating angle $\theta_{A}$ could become enormous. If $\theta_{A} \geq \theta_{t h}$ holds, the auxiliary pin will contact the slot's boundary to lock the swingarm with link $C$. Under this condition, the swingarm can no longer rotate such that the rear brake takes all the magnitude of the input force $F$. On the other hand, with rear brake failure, the swingarm loses the brake wire resisting force acting on the roller $\mathrm{R}$, and the input force $F$ makes the swingarm rotate clockwise freely. Consequently, both the front and rear brake receive no braking forces on the application of $F$. The value of $\theta_{t h}$ is a compromise between the required deceleration on front brake failure and the maximum desired $R_{f}$ value in a normal condition. In this study, $\theta_{t h}=6^{\circ}$ is selected.

The straight-line braking test is carried out on the studied motorcycle to verify the performance of the VCBS. The measurement system includes the VBOX speed sensor to acquire speed, deceleration, and braking distance; a handbrake meter to measure the driver's input force; a hydraulic pressure transducer installed on the caliper of the front brake, and a force sensor installed on the rear brake wire, as shown in Figure 12. The tests [22] are performed by a skilled driver on a standard road condition with an adhesion coefficient of about 0.9 . When the vehicle accelerates to more than $60 \mathrm{~km} / \mathrm{h}$ and reaches the brake start sign on the roadside, the driver presses the left handbrake lever (with force not larger than or equal $200 \mathrm{~N}$ within $0.6 \mathrm{~s}$ ) to activate the VCBS and stop the motorcycle in an emergency. When the motorcycle stops, the braking distance is measured, and the recorded data during braking are stored.

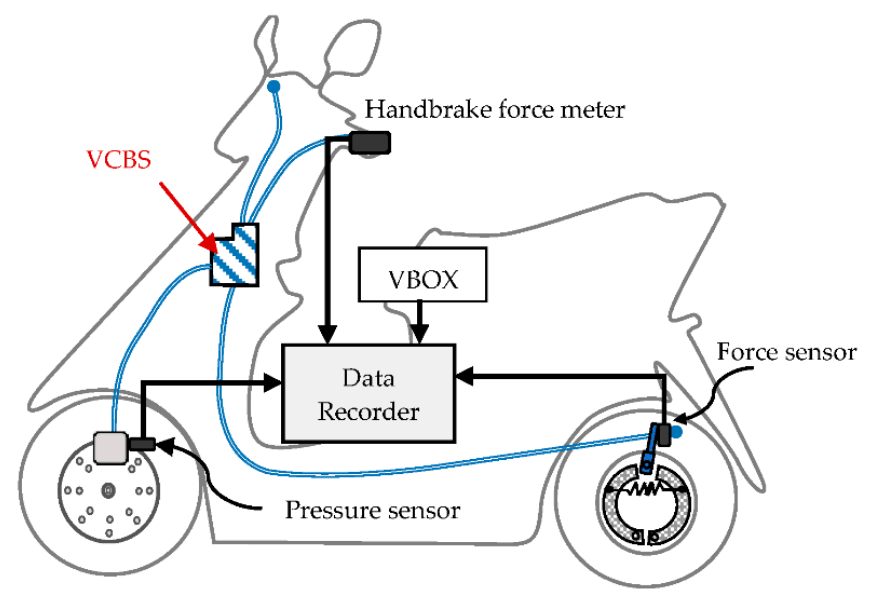

Figure 12. The layout of the VCBS prototype and the associated measurement system.

Table 2 presents three test cycles' recorded data, including the averaged maximum left handlever force, brake triggering speed, MFDD (Mean Fully Developed Deceleration) [22,23], and braking distance. The test results show that, with the averaged maximum handbrake lever force of $190.54 \mathrm{~N}$, the averaged MFDD is $6.37 \mathrm{~m} / \mathrm{s}^{2}-$ much higher than the homologation requirement of $5.1 \mathrm{~m} / \mathrm{s}^{2}(0.52 \mathrm{~g})$.

The dynamic left handbrake lever force, the front braking force calculated from the measured pressure, and the rear braking force during braking are used to plot the BFD curves as shown in Figure 13. There are three performance metrics for the BFD curve concerning braking performance and driving comfort: $P a, P b$, and $P c$. The dimensionless rear braking force $F_{r t} / \mathrm{W}$ at point $\mathrm{Pa}$ represents the dimensionless delaying force of the front brake. A sufficiently large value of $F_{r t} / \mathrm{W}$ at point $\mathrm{Pa}$ can avoid the occurrence of rollover accidents caused by the front wheel locking first for all road conditions and help lower the motorcycle's pitch rate on low braking forces operation, thus improving driving comfort. It is the professional drivers' opinion through subjective evaluation that the optimal dimensionless delaying force $\mathrm{Pa}$ for the studied motorcycle is within $0.08<F_{r t} / \mathrm{W}<0.1$ at laden load. The tested result is within an average of 0.09 , which agrees well with the requirement. 
Table 2. Brake distance and deceleration at laden load.

\begin{tabular}{|c|c|c|c|c|c|c|c|c|}
\hline \multirow[b]{2}{*}{ Test No. } & \multicolumn{2}{|c|}{ Left Handlever Force } & \multirow[b]{2}{*}{ Brake Triggering Speed } & \multirow[b]{2}{*}{ MFDD } & \multirow[b]{2}{*}{ Braking Distance } & \multirow[b]{2}{*}{$P a$} & \multirow[b]{2}{*}{$P b$} & \multirow[b]{2}{*}{$P c$} \\
\hline & Max. & Average & & & & & & \\
\hline Unit & & & $\mathrm{km} / \mathrm{h}$ & $\mathrm{m} / \mathrm{s}^{2}$ & m & - & $\mathrm{m} / \mathrm{s}^{2}$ & $\mathrm{~m} / \mathrm{s}^{2}$ \\
\hline Requirement & $\leq 200$ & & $\min (0.9 V \max *, 60) \pm 5$ & $\geq 5.1$ & & & & \\
\hline 1 & 193.87 & 171.71 & 60.13 & 6.27 & 25.54 & 0.09 & 5.78 & 6.58 \\
\hline 2 & 184.96 & 123.90 & 59.95 & 6.34 & 24.38 & 0.09 & 5.78 & 6.44 \\
\hline 3 & 192.78 & 167.25 & 60.93 & 6.49 & 25.6 & 0.10 & 5.74 & 6.61 \\
\hline Average & 190.54 & 154.29 & 60.34 & 6.37 & 25.17 & 0.09 & 5.77 & 6.54 \\
\hline
\end{tabular}

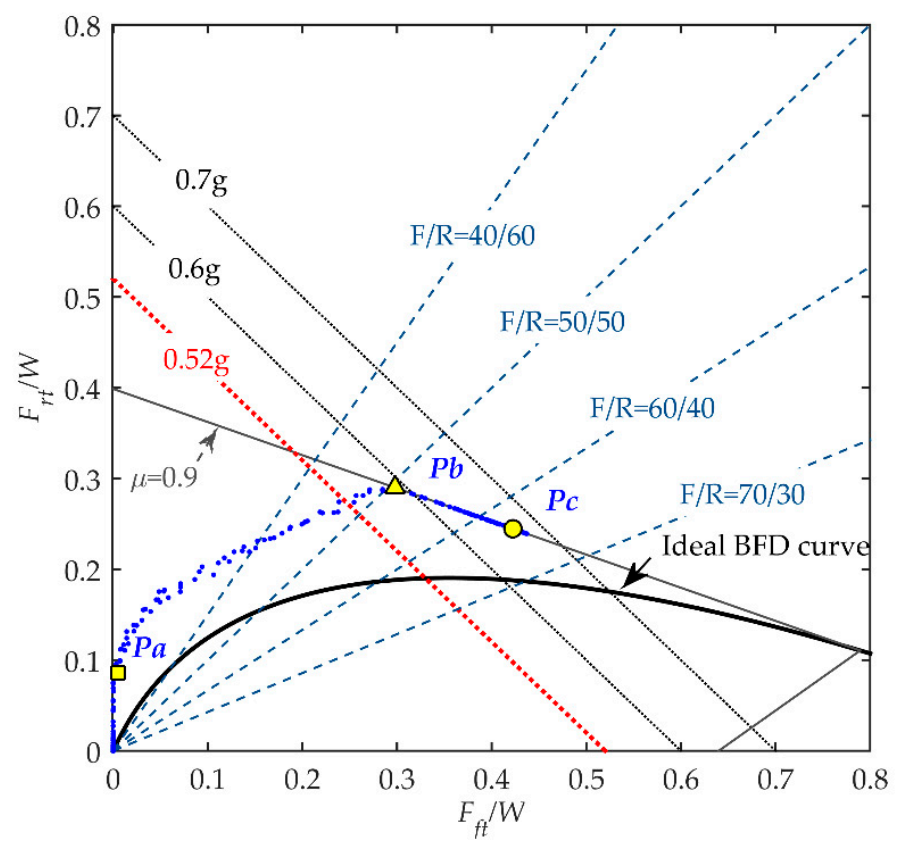

Figure 13. The BFD curves of the straight-line braking test.

$\mathrm{Pb}$ is the point where the BFD curve intersects with the line $\mu=0.9$ and the rear tire starts to skid. At this point, the values of the braking force distribution ratio of wheels $\left(R_{B F D}\right)$, which is defined in Equation (8), and the deceleration are of interest. It is required that the deceleration at $\mathrm{Pb}$ is as high as possible to achieve high braking performance. A higher value of $R_{B F D}$ is required to obtain higher deceleration corresponding to $\mathrm{Pb}$, which is the purpose of the VCBS design. The curve shows that the averaged deceleration corresponding to the point $P b$ is $5.77 \mathrm{~m} / \mathrm{s}^{2}(0.59 \mathrm{~g})$ and $R_{B F D}=0.507$.

After passing through the point $\mathrm{Pb}$, deceleration is increased with the increase of the input force $F$ due to the increase of the front braking force $\left(F_{f t}\right)$. Since the deceleration of the motorcycle, contributed to by the rear braking force, is decreased, the slope of the BFD curve is turned negatively. The curve ceases at the point $P_{c}$ corresponding to the maximum input force. The estimated averaged maximum deceleration at $P c$ is calculated as $6.54 \mathrm{~m} / \mathrm{s}^{2}$, which approaches the averaged MFDD test result of $6.37 \mathrm{~m} / \mathrm{s}^{2}$. For the front brake failure mode test, the tested MFDD is with an average of $3.38 \mathrm{~m} / \mathrm{s}^{2}$, higher than the $2.9 \mathrm{~m} / \mathrm{s}^{2}$ of homologation requirement, as listed in Table 3. All the road test results verify that the VCBS prototype can achieve satisfying deceleration performance and driving comfort. 
Table 3. Braking performance on front brake failure at laden load.

\begin{tabular}{|c|c|c|c|c|c|}
\hline \multirow[b]{2}{*}{ Test No. } & \multicolumn{2}{|c|}{ Left Handlever Force } & \multirow[b]{2}{*}{ Brake Triggering Speed } & \multirow[b]{2}{*}{ MFDD } & \multirow[b]{2}{*}{ Braking Distance } \\
\hline & Max. & Average & & & \\
\hline Unit & \multicolumn{2}{|c|}{$\mathbf{N}$} & $\mathrm{km} / \mathrm{h}$ & $\mathrm{m} / \mathrm{s}^{2}$ & $\mathbf{m}$ \\
\hline Requirement & $\leq 250$ & & $\min \left(0.9 V_{\max } *, 60\right) \pm 5$ & $\geq 3.0$ & \\
\hline 1 & 148.65 & 103.46 & 60.04 & 3.37 & 41.54 \\
\hline 2 & 144.47 & 94.72 & 60.63 & 3.39 & 42.33 \\
\hline Average & 146.56 & 99.09 & 60.34 & 3.38 & 41.94 \\
\hline
\end{tabular}

\section{Conclusions and Remarks}

The VCBS is a mechanism for motorcycles that simultaneously meets safety, high braking performance, and driving comfort requirements. Except for its geometrical dimensions, the critical parameters for the VCBS are the cam profile and the stiffnesses of the returning spring. This paper derives a mathematical model for the VCBS mechanism. A parameter matching design method, based on adaptive control theory, is developed to design the cam profile. The simulation results show that the design method can generate an optimal cam profile to realize any target braking force distribution curve for a specific parameter combination and the spring rates.

A prototype of the VCBS is designed and developed based on the proposed design method in this paper. The road test results show that the motorcycle equipped with the VCBS prototype achieves high deceleration and driving comfort, verifying the feasibility of the proposed design method. It is worth remembering that the adaptive law is designed to make the BFD curve of the VCBS to track the target braking force distribution curve for a given parameter set and spring rates combination. An inappropriate combination of parameters and spring rates may result in an impractical cam profile. Therefore, fine-tuning the parameters of the VCBS, spring rates, reference model, and convergence rate is required in the design process.

Author Contributions: Methodology, software, validation and writing, Y.-T.L.; conceptualization and validation, C.-Y.T.; writing review and supervision, J.-H.K. and Y.-M.H. All authors have read and agreed to the published version of the manuscript.

Funding: This research was funded by the Ministry of Science and Technology, Taiwan (MOST-1092637-E-020-002).

Institutional Review Board Statement: Not applicable.

Informed Consent Statement: Not applicable.

Data Availability Statement: Not applicable.

Acknowledgments: The authors acknowledge the support of Ming Horng Industrial Co., Ltd., Taiwan, in supplying the VCBS prototype, conducting field tests, and technical discussions in this study.

Conflicts of Interest: The authors declare no conflict of interest.

\section{References}

1. Yukimasa, N.; Kanau, I.; Tetsuo, T.; Yoshiaki, S. Research on dual combined brake system (Dual-CBS) for motorcycle. HONDA R D Tech. Rev. 1993, 5, 100-108.

2. Ghosh, S.; Samy, B.A.; Balwada, R.S.; Kaushik, R. Mechanical combined braking system design and validation for scooter. $S A E$ Pap. 2014. [CrossRef]

3. Tetsuo, T.; Kanau, I.; Yoshiaki, S.; Yukimasa, N.; Hiroyuki, N. Further research on new combined brake system (dual CBS) for motorcycles. HONDA R D Tech. Rev. 1994, 6, 194-201. 
4. Soni, L.; Domala, D.; Venkateswaran, S. Combi brake system (CBS) design and tuning on an electric two wheeler for cornering maneuver. SAE Pap. 2019. [CrossRef]

5. Tani, K.; Nakamura, H. Development of advanced brake system for small motorcycles. SAE Pap. 2015. [CrossRef]

6. Tseng, C.; Chiu, Y.; Lin, Y.; Teng, C. High Degree of Variation Ratio Range of Brake Interlocking Braking System. Taiwan Patent 1593593, 1 August 2017.

7. Müller, M.; Hüsing, M.; Beckermann, A.; Corves, B. Linkage and cam design with MechDev based on non-uniform rational B-splines. Machines 2020, 8, 5. [CrossRef]

8. Cardona, A.; Géradin, M. Kinematic and dynamic analysis of mechanisms with cams. Comput. Methods Appl. Mech. Eng. 1993, 103, 115-134. [CrossRef]

9. Fisette, P.; Péterkenne, J.M.; Vaneghem, B.; Samin, J.C. A multibody loop constraints approach for modelling cam/follower devices. Nonlinear Dyn. 2000, 22, 335-359. [CrossRef]

10. Limpert, R. Brake Design and Safety, 3rd ed.; SAE International: Warrendale, PA, USA, 2011; pp. $213-228$.

11. Cossalter, V. Motorcycle Dynamics, 2nd ed.; LuLu: Morrisville, NC, USA, 2006; pp. 97-104.

12. Qiu, D.; Paredes, M.; Seguy, S. Variable pitch spring for nonlinear energy sink: Application to passive vibration control. J. Mech. Eng. Sci. 2019, 233, 611-622. [CrossRef]

13. Ioannou, P.; Fidan, B. Adaptive control for discrete-time systems. In Adaptive Control Tutorial; Smith, R.C., Antoulas, A.C., Eds.; Society for Industrial and Applied Mathematics: Philadelphia, PA, USA, 2006; pp. 255-258.

14. Slotine, J.; Li, W. Adaptive control. In Applied Nonlinear Control; Prentice Hall: Upper Saddle River, NJ, USA, 1991 ; pp. $326-335$.

15. Zhao, L.; Choi, K.; Lee, I. A metamodeling method using dynamic Kriging and sequential sampling. AIAA J. 2010, 49, 2034-2046. [CrossRef]

16. Simpson, T.W.; Toropov, V.; Balabanov, V.; Viana, F.A.C. Design and analysis of computer experiments in multidisciplinary design optimization: A review of how far we have come-or not. In Proceedings of the 12th AIAA/ISSMO Multidisciplinary Analysis and Optimization Conference, Victoria, BC, Canada, 10-12 September 2008.

17. Mercorelli, P. Parameters identification in a permanent magnet three-phase synchronous motor of a city-bus for an intelligent drive assistant. Int. J. Model. Identif. Control. 2014, 21, 352-361. [CrossRef]

18. Chen, L.; Mercorelli, P.; Liu, S. A Kalman estimator for detecting repetitive disturbances. In Proceedings of the 2005 American Control Conference, Portland, OR, USA, 8-10 June 2005; Volume 3, pp. 1631-1636.

19. Kim, C.; Wang, S.; Choi, K.K. Efficient response surface modeling by using moving least-squares method and sensitivity. AIAA J. 2005, 43, 2404-2411. [CrossRef]

20. Lancaster, P.; Salkauskas, K. Surfaces generated by moving least squares methods. Math. Comput. 1981, 37, 141-158. [CrossRef]

21. Johansson, R. System Modeling and Identification; Prentice-Hall: Englewood Cliffs, NJ, USA, 1993; pp. $266-267$.

22. The United Nations Economic Commission for Europe. Global Technical Regulation No.3: Motorcycle Brake Systems; No. ECE/TRAN/180/Add.3; UNECE: Geneva, Switzerland, 2006.

23. Racelogic support centre. 18-VBOX Tools Test Configurations. Available online: https://racelogic.support/01VBOX_Automotive/03 Software_applications/VBOX_Tools/VBOX_Tools_User_Manual/18_-_VBOX_Tools_Test_Configurations (accessed on 8 January 2021). 